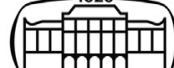

AKADÉMIAI KIADÓ

UNIVERSITY of DEBRECEN

\section{International Review of Applied Sciences and Engineering}

12 (2021) 3, 301-311

DOI:

$10.1556 / 1848.2021 .00284$

(c) 2021 The Author(s)

\section{CASE STUDY}

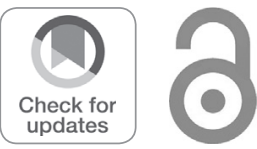

\title{
Productivity index of horizontal well in Mishrif formation of Buzurgan oil field - Case study
}

\author{
Ghazwan N S Jreou* \\ Chemical Engineering Department, Engineering Faculty, University of Kufa, Iraq
}

Received: April 2, 2021 - Accepted: June 2, 2021

Published online: July 17, 2021

\begin{abstract}
Horizontal good technology is one of the recent methods in the drilling and exploitation of geological formations in the best and optimal ways, because of the many and comprehensive advantages that these wells enjoy with the most important measurement and prediction index called productivity index. Which is equivalent to several times higher than the vertical well productivity index, if the field is invested by drilling vertical wells only.

The current research focuses on calculating the productivity index by proposing the development point of view of the reservoir formation in the Burgan oil field through the production of oil from the production units approved in the formation (MB21, MC1, MC2) by using of horizontal good technology and comparing it with the value of the productivity index of vertical wells in the same production units.

Well-known published methods adopted in the case of steady state and pseudo steady state were used in the calculations of the productivity index, and by comparison with the standard observed results, it was found that the Joshi method was closer than others in the calculations of the productivity index for both steady and pseudo steady state cases. Then the calculations were completed taking into account all conditions and factors that have a significant role in the value of the calculated productivity index.

The obtained results revealed that PI increases with [well length, isotropy ratio $(\mathrm{Kv} / \mathrm{Kh})$, well thickness vs. well length] increase, while it was decreased with [ drainage area] increase in the case of steady state conditions. Also, the PI increase with length increase in the case of Pseudo steady state condition for all the studied methods, and both of Kuchuck and Economides methods seem to be close in obtained results, but Economides is the closest one to the reality and importance in application with the present case. Completion configuration has an effluence on the PI, and it is increasing with the increase of well opening to the production for such well length.

Also, all the results indicated that the use of this type of technology in the field development is good and promising, and gave valuable, excellent, and optimistic results for the future production of the field in a profitable manner.
\end{abstract}

\section{KEYWORDS}

productivity index, horizontal well, Mishrif formation, Buzurgan oil field

\section{INTRODUCTION}

The technology of drilling horizontal wells constituted a qualitative leap in the world of oil engineering, as companies began to compete to use technology and develop it in the direction of increasing production and optimal use of natural resources such as crude oil and natural gas and reducing the costs of invested capital.

Mainly horizontal well drill to increase the production of oil or gas in comparison with vertical wells, and when the decision of both production and reservoir engineers (reservoir management) is pointing towards the development of oil and gas fields by using the horizontal wells technology, then it is necessary to take into consideration the percentage of the productivity of horizontal wells versus the productivity of vertical wells, in addition to the 
properties of both the reservoir and the well as a whole, knowing that this percentage of the productivity was considered to the good pressure is constant.

Also, from the data extracted from this percentage of productivity, we find that the horizontal wells have 2-3 times higher productivity than the vertical wells, and this will certainly be adopted. The length of the drilled horizontal section and the density of perforation areas along the section affect on well productivity.

In the case of such reservoirs where the oil is under potential conditions that make it have one phase (undersaturated), we find that the yield of its wells will be proportional to the value of the pressure drop between the reservoir pressure and the good pressure; this factor of proportionality is represented by the productivity index PI, which is denoted by the letter ' $J$ ' and its unit is 'STB/D/Pisa', this parameter quantifies the ability of the reservoir to give up a quantity of oil in barrels per day in exchange for a pressure drop, whereas an inflow performance relationship is a measure of the ability of the formation or layer to produce a certain amount of oil and gas that can be controlled by PI.

It was clear from the studies and researches dealt with or included in this regard that many factors affect the amount of pressure in both layers and the well together, and thus affect the productivity of wells. These factors include, among others, reservoir drainage area, pay zone thickness, reservoir isotropy $(\mathrm{Kv} / \mathrm{Kh})$, well length and fluid properties.

Other productive design factors affect the amount of pressure drop, which are related to the nature of the wells' completion, like perforations, partial penetrations, gravel pack as well as damage due to drilling and completions.

Accordingly, it can be considered that the PI is a valuable methodology through which it is possible to predict or extrapolate the performance of productive wells or reservoirs in general.

\subsection{Objective of the work}

The main objective of this work was to investigate the comparative study of different horizontal well productivity index models for Mishra Formation in the Buzurgan oil field as a case study.

\subsection{Methodology}

To study the possibility of implementing horizontal wells by calculating the productivity index PI in the Mishrif formation of the Buzurgan oil field according to different published models for both steady and pseudo steady state of a reservoir, this includes the following steps: -

1.2.1. Extracting the necessary field data from technical reports and field information.

1.2.2. Conducting the first step of calculations for the productivity Index PI with the most acceptable and published methods in the case of the steady state, taking into account all factors and variables affecting the calculations. Conducting the second part of calculations for the productivity Index PI with the most acceptable and published methods in the case of the pseudo steady state, taking into account all factors and variables affecting the calculations.

1.2.3. A comparison of the calculations for both steps with the reality of the situation and the indicator in the field measurements to know the extent of validity and reliability of the calculations and the accuracy of the adopted chosen model in each case, under validation PI model section.

1.2.4. Conducting the conclusions for the research with recommendations.

\subsection{Buzurgan oil field}

The Buzurgan oil field is located in the South-Eastern part of the Republic of IRAQ, close to the Iran boundary, $40 \mathrm{Km}$ North East of Amara. The oil field was discovered in 1970, and in November 1976 its development was started. The oil field development was carried out by the general organization of south oil - Missan Oil field. Figure 1 shows the geographical location of the Buzurgan oil field, while Fig. 2 shows the formation stratigraphy in the field.

The structure of the field is an elongated fold consisting of two domes north and south, separated by a shallower saddle along the longitudinal axis of the structure. The main reservoir in the field is Mishrif formation, which is composed of three units, which are also divided into layers depending on the difference in the different depositional environmental and petrophysical properties. Among these units, MB21, MC1 And MC2 are better because of their properties and amount of oil reserve.

\section{STRATIGRAPHY1}

Buzurgan geological structure is composed of Tertiary and Upper cretaceous deposits. Lower deposits were not penetrated. Stratigraphy description is made according to data given in the final geological reports for Buzurgan wells, these reports are specialist for Missan oil company (operator of the field), for review but not for publishing.

\subsection{Mishrif formation}

The top is characterized by an unconformity. The formation is presented by limestone of white, light-brown, and brown color due to oil stain; it is presented by crystalline to microcrystalline limestone, by soft to medium-hard limestone, recrystallized and chalky in some parts with bioclastic, cavernous and sometimes limestone interbeds (mudstone, wackestone, packstone, grainstones). Thickness is $331-373 \mathrm{~m}$.

The Mishrif formation covered from the top by the alKhatib formation, where the al-Rumaila formation comes to the bottom, and the total thickness reaches about $340 \mathrm{~m}$. The formation is divided into three main units (MB21, MC1, and $\mathrm{MC2}$ ), and these units in turn were divided into secondary layers depending on the difference in the rock facies as a result of a change in environmental conditions during sedimentation.

The bottom part of the formation consists of limestone chalk rocks with a semi-basin environment and represents a 


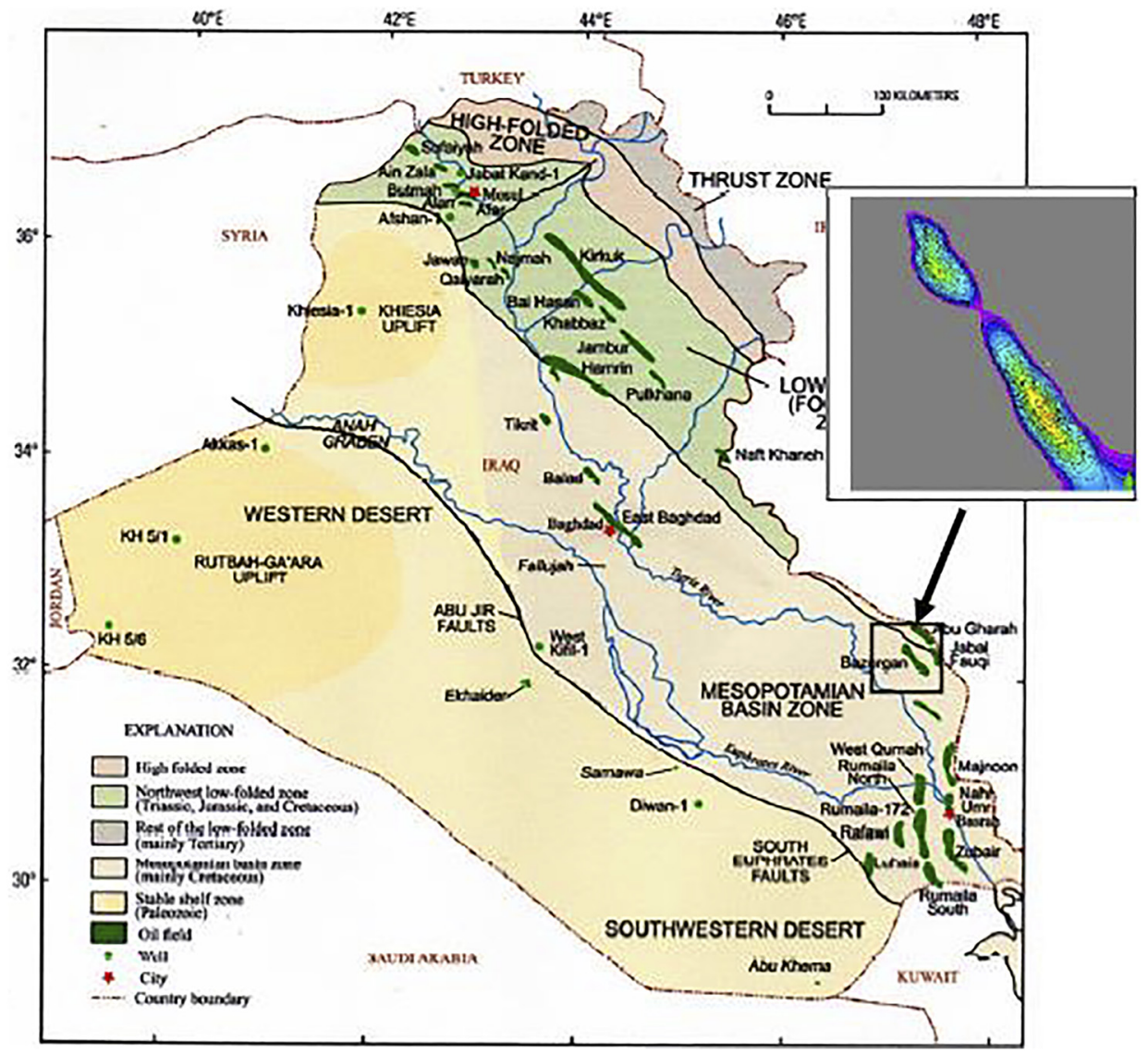

Fig. 1. Location of Buzurgan oil field after ref. [1]

transitional stage between the deep marine environment of Rumaila and the local environment of coral aggregations that represent the middle part of the formation. These agglomerations are of great importance because they have good porosity and permeability and contain good quantities of oil.

The upper part of the formation consists of limestone rocks, which have an environment of tide up, that forms the rock cover of the reservoir.

\section{MB21}

It is considered one of the most important formation units, as it has good quantitative properties and contains the highest percentage of oil reserve, and its thickness ranges between 72 and $91 \mathrm{~m}$. The porosity ranges between 13.3 and $17.6 \%$ and the permeability rate is less than $10 \mathrm{~mm}$. OWC at a depth of 3,875 $\mathrm{m}$ in the Northern dome and 3,891 $\mathrm{m}$ in the southern dome measured from sea level. the facies in this unit are graded from facies with high porosity and low permeability to shallower facies left in the middle and top of this unit, which are granular rocks deposited in high energy conditions with high initial porosity and high avoidance, in the form of a high production area in this unit.

\section{MC1}

The second important formation unit which has a thickness ranges within $61-97 \mathrm{~m}$ and porosity of $12.5-17.5 \%$ and permeability less than $20 \mathrm{md}$. The OWC located at depth of 3,994 $\mathrm{m}$ in the northern dome while at 3,950.6 $\mathrm{m}$ in the southern dome measured from sea level. Most of the rock unit consists of lagoon facies of low porosity interbedded with wedding Rhodes, which make it reservoir rocks having good properties of primary porosity and permeability.

\section{MC2}

The third formation unit has a thickness range of 29-45 $\mathrm{m}$ and a porosity of $11-15.8$. The OWC is located at depth of $3,982 \mathrm{~m}$ in the northern dome while at $3,995 \mathrm{~m}$ in the southern dome measured from sea level. Most of the rock units consist of wacky limestone to muddy limestone precipitates in conditions of a slope to the basin, and it is a chalky habit in most parts of it. It is characterized by high porosity and poor permeability, except that the surface of the particle recession may improve the permeability due to the expectation of cracks in it with the presence of some Rhodian clusters.

\section{RESERVOIR AND WELL DATA}

As mentioned before, the main reservoir in the Buzurgan oil field is Mishrif formation with $206 \mathrm{~m}$ thickness, and it is consisting of three productive layers (MB21, MC1, and MC2) which were detailed before. The following table includes the main input data for the calculations of the Productivity index for both MB21 and MC1 layers where the 


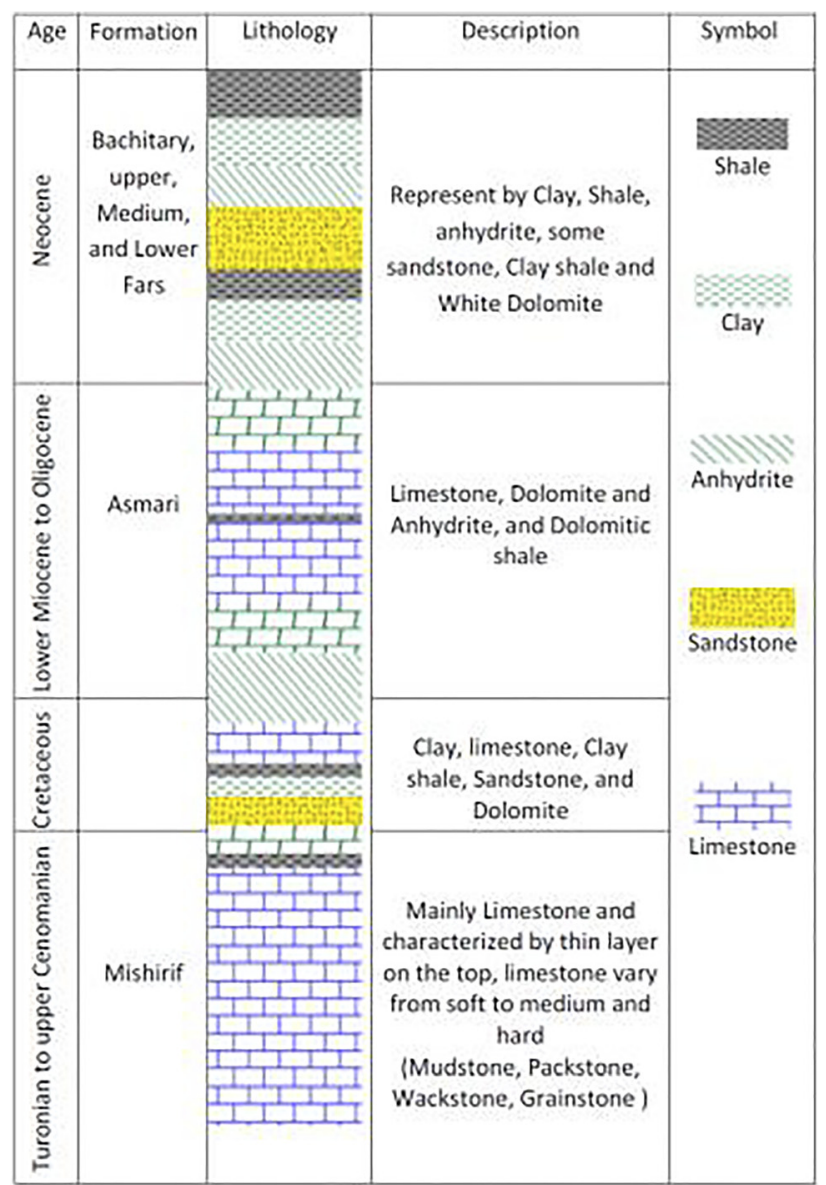

Fig. 2. Stratigraphy description for Buzurgan structure after ref. [1]

MC@ layer was excluded because of lack of data obtained, in addition to the fact that the layer is characterized by poor physical properties.

\section{CALCULATIONS OF PI}

\subsection{Steady state condition}

Under the steady state condition, the reservoir pressure is constant everywhere in a reservoir and this needs a pressure potential to substitute the pressure drops due to production from wells in the reservoir. Joshi [2] explains why this type of solution is more preferred and desirable according to: -

- They are easy to derive analytically

- It is fairly easy to convert results of steady state to either transient or pseudo steady state results by using concepts of expanding of drainage boundary over time and effective good radius and shape factor respectively

- The results of mathematical modeling of steady state can be verified experimentally.

Several solutions are published in the literature to perform and predict the steady state productivity index in a horizontal well, those are: -

4.1.1. Borisove Model [3]
4.1.2. Giger [4]

4.1.3. Joshi Model [2]

4.1.4. Renard and Dupuy model [5]

All the mathematical models are explained in detail within Appendix A.

\subsection{Pseudo steady state}

Under pseudo steady condition, the good boundary drainage area was felt by pressure drop due to well production and made the fluid at its side moving toward the well. Whatever the shape of the drainage area (depends on permeability isotropy), when the pressure disturbance due to well production reaches all the boundaries, the pseudo steady state begins, so the time required for that is $(t=948 \phi \mu \mathrm{ctre} 2 / \mathrm{k})$.

Also, in this condition state, the reservoir must have closed boundaries and there should be no flow across it. The pseudo steady state solution is suitable for predicting well performance in the depletion stage of the reservoir, and productivity index under this condition can be performed within average reservoir pressure that was estimated by well testing (build up or drawdown). Some of the methods were published in the literature to calculate the pseudo steady state productivity index for horizontal wells for single-phase flow with assumptions, like: -

- The reservoir is assumed bounded in all directions

- The horizontal well was arbitrarily located within a rectangular bounded drainage area

Joshi [2] explained three methods of PI calculation according to their differences in well consideration, those are: -

- Method I, assumes the well as infinite conductivity

- Method II, assumed a uniform flux boundary condition

- Method III, uses an approximate infinite conductivity with constant wellbore pressure (averaging pressure values of uniform flux along the well length).

There are four pseudo steady state equations published in literatures to measure the productivity index of horizontal oil wells, these are: -

4.2.1. Joshi Model [2]

4.2.2. Babu and Odeh Model [6]

4.2.3. Kuchuk model [7]

4.2.4. Economides Model [8]

All the mathematical models are explained in detail within Appendix A.

Calculations of PI with different models. The general input data for this section were taken from ref. [9], and according to the different petrophysical properties, the main reservoir in the field is Mishrif formation which was divided into 3 main productive Layers (MB21, MC1, MC2) - Table 1 includes the important data for each layer that were used with the PI models and correlations; Table 2 shows the results of PI calculations according to the steady state methods explained in the previous section as a base case.

While Tables 3-10, shows the final calculation results in regard to different parameters that affect PI in each model. 
Table 1. Reservoir, fluid and well data

\begin{tabular}{lccc}
\hline Layer & Reservoir Data & Fluid Data & Well Data \\
\hline MB21 & Kh $=10 \mathrm{md}$ & $\mu_{\mathrm{o}}=1.15661 \mathrm{c.p}$ & $\mathrm{L}=1,000 \mathrm{ft}$ \\
& $\mathrm{Kv}=10 \mathrm{md}$ & $\mathrm{B}_{\mathrm{o}}=1.3825$ & $\mathrm{Rw}=0.365 \mathrm{ft}$ \\
& $\mathrm{H}=81.5 \mathrm{~m}$ & $\mathrm{RB} / \mathrm{STB}$ & $\mathrm{Reh}=1,640 \mathrm{ft}$ \\
& Tres $=235$ & & $\mathrm{~A}=194 \mathrm{acres}$ \\
& Pres $=6,128.7$ Psia & & \\
MC1 & $\Phi=15 \%$ & $=$ \\
& $\mathrm{Kh} \leq 20 \mathrm{md}$ & & \\
& $\mathrm{Kv} \leq 20 \mathrm{md}$ & & \\
& $\mathrm{H}=79 \mathrm{~m}$ & & \\
& Tres $=235$ & & \\
& Pres $=6,128.7$ Psia & & \\
\hline
\end{tabular}

Table 2. Results of the PI with different methods. (Base Case)

\begin{tabular}{lc}
\hline PI - Method & Pi - STB/D/Psia \\
\hline Borisove Model & 3.754 \\
Joshi Model & 13.763 \\
Gigers Model & 3.783 \\
Renard and Dupuy Model & 3.754 \\
\hline
\end{tabular}

For MB21 formation layer.

a. Effect of horizontal well length $(\mathrm{Kv} / \mathrm{Kh}=1.0)$

Table 3. Effect of horizontal well length

\begin{tabular}{lrrrr}
\hline & \multicolumn{4}{c}{ Horizontal Well Length } \\
\cline { 2 - 5 } PI - Method & $1,000 \mathrm{ft}$ & $1,500 \mathrm{ft}$ & $2,000 \mathrm{ft}$ & $2,500 \mathrm{ft}$ \\
\hline Borisove Model & 3.754 & 5.095 & 6.49 & 8.034 \\
Joshi Model & 13.763 & 15 & 17.547 & 21.129 \\
Gigers Model & 3.783 & 5.223 & 6.905 & 9.251 \\
Renard and Dupuy Model & 3.754 & 5.092 & 6.475 & 7.978 \\
\hline
\end{tabular}

\section{c. Effect of well thickness Vs. well length}

Table 5. Effect of well thickness Vs. well length

\begin{tabular}{|c|c|c|c|c|}
\hline $\begin{array}{l}\text { Well } \\
\text { Length - Ft }\end{array}$ & PI Method & & & \\
\hline \multirow[t]{5}{*}{1,000} & & 0.3 & 0.5 & 1.0 \\
\hline & Borisove Model & 1.639 & 2.442 & 3.754 \\
\hline & Joshi Model & 2.1313 & 4.064 & 13.763 \\
\hline & Gigers Model & 1.658 & 2.466 & 3.783 \\
\hline & $\begin{array}{c}\text { Renard and Dupuy } \\
\text { Model }\end{array}$ & 1.639 & 2.441 & 3.754 \\
\hline \multirow[t]{4}{*}{1,500} & Borisove Model & 2.132 & 3.221 & 5.095 \\
\hline & Joshi Model & 2.664 & 4.963 & 15 \\
\hline & Gigers Model & 2.208 & 3.324 & 5.223 \\
\hline & $\begin{array}{c}\text { Renard and Dupuy } \\
\text { Model }\end{array}$ & 2.131 & 3.218 & 5.092 \\
\hline \multirow[t]{4}{*}{2,000} & Borisove Model & 2.67 & 4.056 & 6.49 \\
\hline & Joshi Model & 3.275 & 6.0474 & 17.547 \\
\hline & Gigers Model & 2.909 & 4.384 & 6.905 \\
\hline & $\begin{array}{c}\text { Renard and Dupuy } \\
\text { Model }\end{array}$ & 2.661 & 4.044 & 4.75 \\
\hline \multirow[t]{4}{*}{2,500} & Borisove Model & 3.604 & 5.0 & 8.034 \\
\hline & Joshi Model & 4.508 & 7.361 & 21.131 \\
\hline & Gigers Model & 4.379 & 5.991 & 9.252 \\
\hline & $\begin{array}{c}\text { Renard and Dupuy } \\
\text { Model }\end{array}$ & 3.57 & 4.965 & 7.978 \\
\hline
\end{tabular}

\section{b. Effect of an isotropy (Kv/Kh)}

Table 4. Effect of an isotropy

\begin{tabular}{|c|c|c|c|c|c|c|}
\hline \multirow{2}{*}{$\frac{\text { Well Length }-\mathrm{Ft}}{1,000}$} & \multirow[t]{2}{*}{ PI Method } & \multicolumn{5}{|c|}{$\mathrm{Kv} / \mathrm{Kh}$} \\
\hline & & 0.1 & 0.25 & 0.5 & 0.75 & 1.0 \\
\hline & Borisove Model & 3.754 & 3.754 & 3.754 & 3.754 & 3.754 \\
\hline & Joshi Model & - & 56.426 & 20.832 & 15.856 & 13.763 \\
\hline & Gigers Model & 11.963 & 7.566 & 5.35 & 4.368 & 3.783 \\
\hline & Renard and Dupuy Model & 3.754 & 3.754 & 3.754 & 3.754 & 3.754 \\
\hline \multirow[t]{4}{*}{1,500} & Borisove Model & 5.095 & 5.095 & 5.095 & 5.095 & 5.095 \\
\hline & Joshi Model & -- & 33.911 & 19.996 & 16.612 & 15 \\
\hline & Gigers Model & 16.515 & 10.445 & 7.386 & 6.031 & 5.223 \\
\hline & Renard and Dupuy Model & 5.096 & 5.096 & 5.096 & 5.096 & 5.092 \\
\hline \multirow[t]{4}{*}{2,000} & Borisove Model & 6.49 & 6.49 & 6.49 & 6.49 & 6.49 \\
\hline & Joshi Model & 277.227 & 34.551 & 22.511 & 19.192 & 17.547 \\
\hline & Gigers Model & 21.835 & 13.809 & 9.765 & 7.973 & 6.905 \\
\hline & Renard and Dupuy Model & 6.475 & 6.475 & 6.475 & 6.475 & 6.475 \\
\hline \multirow[t]{4}{*}{2,500} & Borisove Model & 8.034 & 8.034 & 8.034 & 8.034 & 8.034 \\
\hline & Joshi Model & 222.3 & 40.268 & 26.845 & 23.035 & 21.129 \\
\hline & Gigers Model & 29.26 & 18.503 & 13.083 & 10.683 & 9.251 \\
\hline & Renard and Dupuy Model & 7.978 & 7.978 & 7.978 & 7.978 & 7.978 \\
\hline
\end{tabular}


d. Effect of drainage area Vs. an isotropy (well length = $1,000 \mathrm{ft}$ )

Table 6. Effect of drainage area Vs. an isotropy

\begin{tabular}{|c|c|c|c|c|c|}
\hline Drainage area - acres & PI Method & & & & \\
\hline \multirow[t]{5}{*}{50} & & 0.25 & 0.5 & 0.75 & 1.0 \\
\hline & Borisove Model & 4.781 & 4.781 & 4.781 & 4.781 \\
\hline & Joshi Model & - & - & 162.241 & 63.474 \\
\hline & Gigers Model & 10 & 7.063 & 5.767 & 5 \\
\hline & Renard and Dupuy Model & 4.774 & 4.774 & 4.774 & 4.774 \\
\hline \multirow[t]{4}{*}{100} & Borisove Model & 4.194 & 4.194 & 4.194 & 4.194 \\
\hline & Joshi Model & - & 49.706 & 28.424 & 22.336 \\
\hline & Gigers Model & 8.535 & 6.035 & 4.928 & 4.268 \\
\hline & Renard and Dupuy Model & 4.193 & 4.193 & 4.193 & 4.193 \\
\hline \multirow[t]{4}{*}{150} & Borisove Model & 3.914 & 3.914 & 3.914 & 3.914 \\
\hline & Joshi Model & 145.35 & 26.911 & 19.146 & 16.178 \\
\hline & Gigers Model & 7.91 & 5.593 & 4.567 & 3.955 \\
\hline & Renard and Dupuy Model & 3.913 & 3.913 & 3.913 & 3.913 \\
\hline \multirow[t]{4}{*}{200} & Borisove Model & 3.736 & 3.736 & 3.736 & 3.736 \\
\hline & Joshi Model & 52.597 & 20.287 & 15.539 & 13.523 \\
\hline & Gigers Model & 7.528 & 5.323 & 4.346 & 3.764 \\
\hline & Renard and Dupuy Model & 3.736 & 3.736 & 3.736 & 3.736 \\
\hline \multirow[t]{4}{*}{250} & Borisove Model & 3.609 & 3.609 & 3.609 & 3.609 \\
\hline & Joshi Model & 35.166 & 17.031 & 13.554 & 12 \\
\hline & Gigers Model & 7.259 & 5.133 & 4.191 & 3.629 \\
\hline & Renard and Dupuy Model & 3.609 & 3.609 & 3.609 & 3.608 \\
\hline
\end{tabular}

Formation layer (MC1).

a. Effect of horizontal well length $(\mathrm{Kv} / \mathrm{Kh}=1.0)$

Table 7. Effect of well length

\begin{tabular}{lcccc}
\hline PI - Method & \multicolumn{2}{c}{ Horizontal Well Length - Ft } \\
\hline & 1,000 & 1,500 & 2,000 & 2,500 \\
Borisove Model & 7.389 & 10.012 & 12.747 & 15.776 \\
Joshi Model & 25.543 & 28.142 & 33.05 & 39.837 \\
Gigers Model & 7.446 & 10.267 & 13.573 & 18.204 \\
Renard and Dupuy Model & 7.388 & 10.01 & 12.717 & 15.67 \\
\hline
\end{tabular}

\section{b. Effect of an isotropy $(\mathrm{Kv} / \mathrm{Kh})$}

Table 8. Effect of an isotropy

\begin{tabular}{|c|c|c|c|c|c|c|}
\hline \multirow{2}{*}{$\frac{\text { Well Length }-\mathrm{Ft}}{1,000}$} & \multirow[t]{2}{*}{ PI Method } & \multicolumn{5}{|c|}{$\mathrm{Kv} / \mathrm{Kh}$} \\
\hline & & 0.1 & 0.25 & 0.5 & 0.75 & 1.0 \\
\hline & Borisove Model & 7.389 & 7.389 & 7.389 & 7.389 & 7.389 \\
\hline & Joshi Model & - & 83.418 & 37.107 & 29.069 & 25.543 \\
\hline & Gigers Model & 23.547 & 14.893 & 10.531 & 8.598 & 7.446 \\
\hline & Renard and Dupuy Model & 7.388 & 7.388 & 7.388 & 7.388 & 7.388 \\
\hline \multirow[t]{4}{*}{1,500} & Borisove Model & 10.012 & 10.012 & 10.012 & 10.012 & 10.012 \\
\hline & Joshi Model & 155.306 & 58.278 & 36.643 & 30.933 & 28.142 \\
\hline & Gigers Model & 32.467 & 20.534 & 14.519 & 11.855 & 10.267 \\
\hline & Renard and Dupuy Model & 10.01 & 10.06 & 10.01 & 10.01 & 10.01 \\
\hline \multirow[t]{4}{*}{2,000} & Borisove Model & 12.747 & 12.747 & 12.747 & 12.747 & 12.747 \\
\hline & Joshi Model & 254.187 & 60.959 & 41.589 & 35.917 & 33.05 \\
\hline & Gigers Model & 42.92 & 27.145 & 19.194 & 15.672 & 13.573 \\
\hline & Renard and Dupuy Model & 12.717 & 12.717 & 12.717 & 12.717 & 12.717 \\
\hline
\end{tabular}




\section{c. Effect of well thickness Vs. well length}

Table 9. Effect of well thickness Vs. well Length

\begin{tabular}{|c|c|c|c|c|}
\hline $\begin{array}{l}\text { Well } \\
\text { Length - Ft }\end{array}$ & & thod & & \\
\hline 1,000 & & 0.3 & 0.5 & 1.0 \\
\hline & Borisove Model & 3.195 & 4.774 & 7.389 \\
\hline & Joshi Model & 4.1097 & 7.788 & 25.544 \\
\hline & Gigers Model & 3.2313 & 4.822 & 7.446 \\
\hline & $\begin{array}{c}\text { Renard and Dupuy } \\
\text { Model }\end{array}$ & 3.195 & 4.773 & 7.388 \\
\hline 1,500 & Borisove Model & 4.153 & 6.291 & 10.011 \\
\hline & Joshi Model & 5.140 & 9.529 & 28.142 \\
\hline & Gigers Model & 4.3 & 6.494 & 10.267 \\
\hline & $\begin{array}{c}\text { Renard and Dupuy } \\
\text { Model }\end{array}$ & 4.149 & 6.286 & 10.01 \\
\hline 2,000 & Borisove Model & 5.197 & 7.918 & 12.747 \\
\hline & Joshi Model & 6.323 & 11.628 & 33.049 \\
\hline & Gigers Model & 5.666 & 8.565 & 13.572 \\
\hline & $\begin{array}{c}\text { Renard and Dupuy } \\
\text { Model }\end{array}$ & 5.181 & 7.895 & 12.717 \\
\hline 2,500 & Borisove Model & 7.018 & 9.78 & 15.776 \\
\hline & Joshi Model & 8.698 & 14.15 & 39.836 \\
\hline & Gigers Model & 8.538 & 11.71 & 18.204 \\
\hline & $\begin{array}{c}\text { Renard and Dupuy } \\
\text { Model }\end{array}$ & 6.953 & 9.69 & 15.67 \\
\hline
\end{tabular}

d. Effect of drainage area Vs. an isotropy (well length $=$ $1,000 \mathrm{ft}$ )
Pseudo steady state - PI. In accordance with this state of PI calculations, it seems suitable and well applicable for the Buzurgan oil field, because the production history and policy of the field operations and monitoring revealed that the field produces under depletion drive strategy since the first period of production, as well as the calculations of this section proved that clearly. Table 11 presents the results of the PI calculations according to the pseudo steady state methods that were presented before.

Table 11. Pseudo steady sate productivity index

\begin{tabular}{lccc}
\hline & \multicolumn{3}{c}{$\mathrm{PI}-(\mathrm{STB} / \mathrm{D} / \mathrm{Psia})$} \\
\cline { 2 - 4 } Method & $1,000-\mathrm{Ft}$ & $1,500-\mathrm{Ft}$ & $2,000-\mathrm{Ft}$ \\
\hline Mutalik et al. & 4 & 6.4 & 8.68 \\
Babu and Odeh & 0.491 & 0.623 & 0.754 \\
Kuchuck & 5.049 & 6.752 & 8.986 \\
Economides & 5.564 & 8.921 & 13 \\
\hline
\end{tabular}

It is clear from the results of Table 11 that an increase in the good length led to an increase in the productivity index for each psi pressure drop in the reservoir for all the methods, but the method of Economides seems to be the suitable one to mimic the production from the field in comparison with the other methods and observed data

\section{VALIDATION OF PI MODELS}

To make validation for the PI calculations with different Published models under the production circumstances and restrictions (either steady state or pseudo steady state), one can use the observed data for comparison purposes or with

Table 10. Effect of drainage area Vs. an isotropy

\begin{tabular}{|c|c|c|c|c|c|}
\hline Drainage area - acres & PI Method & & & & \\
\hline \multirow[t]{5}{*}{50} & & 0.25 & 0.5 & 0.75 & 1.0 \\
\hline & Borisove Model & 9.451 & 9.451 & 9.451 & 9.451 \\
\hline & Joshi Model & - & - & 198.789 & 102.266 \\
\hline & Gigers Model & 19.761 & 13.973 & 11.409 & 9.88 \\
\hline & Renard and Dupuy Model & 9.435 & 9.435 & 9.435 & 9.435 \\
\hline \multirow[t]{4}{*}{100} & Borisove Model & 8.271 & 8.271 & 8.271 & 8.271 \\
\hline & Joshi Model & - & 79.698 & 50 & 40.408 \\
\hline & Gigers Model & 16.835 & 11.904 & 9.719 & 8.417 \\
\hline & Renard and Dupuy Model & 8.267 & 8.268 & 8.267 & 8.267 \\
\hline \multirow[t]{4}{*}{150} & Borisove Model & 7.708 & 7.708 & 7.708 & 7.708 \\
\hline & Joshi Model & 156.376 & 46.826 & 34.713 & 29.801 \\
\hline & Gigers Model & 15.579 & 11.017 & 8.995 & 7.789 \\
\hline & Renard and Dupuy Model & 7.706 & 7.706 & 7.706 & 7.706 \\
\hline \multirow[t]{4}{*}{200} & Borisove Model & 7.352 & 7.352 & 7.352 & 7.352 \\
\hline & Joshi Model & 79.031 & 36.213 & 28.517 & 25.117 \\
\hline & Gigers Model & 14.816 & 10.476 & 8.554 & 7.408 \\
\hline & Renard and Dupuy Model & 7.352 & 7.352 & 7.352 & 7.352 \\
\hline \multirow[t]{4}{*}{250} & Borisove Model & 7.099 & 7.099 & 7.099 & 7.099 \\
\hline & Joshi Model & 57.109 & 30.796 & 25.048 & 22.386 \\
\hline & Gigers Model & 14.279 & 10.096 & 8.244 & 7.139 \\
\hline & Renard and Dupuy Model & 7.098 & 7.098 & 7.098 & 7.098 \\
\hline
\end{tabular}


simulation results. Herewith our case of horizontal wells production from Mishrif formation in Buzurgan field, no published data were found in the literature, but as a guess from the production of vertical wells and physical properties and by using an analog of another field in the same area in the same formation, one can estimate the well PI range for these types of wells, which are in between 13 and $14 \mathrm{STB} / \mathrm{D} / \mathrm{Psia}$, therefore from the base case results, Joshi [2] was the proper method for calculations of PI under steady state condition, while the Economides method was suitable for the calculation of PI under pseudo steady state condition.

\section{COMPLETION CONFIGURATION ON PRODUCTIVITY INDEX -PI}

This issue discusses the completion configuration effect on well productivity index through studding of skin damage types, as it is found in the literatures [10], there are three types of damage as follows:

1. Skin due to perforation, $S_{P F}$

2. Skin due to penetration, $S_{P}$

3. Skin due to crush zone permeability, $\mathrm{S}_{\mathrm{C}}$

Here, the damage caused by the penetration of the well to the formation layers will be discussed. If the penetration is complete, then the amount of damage is considered equal to zero $\left(S_{P}=0\right)$, while if the penetration is partial, it will be calculated and discussed according to a method of Brons and Marting method [10]. Oaken E. and Oloro J [11], presented a scenario to apply the method of Brons and Martin as follows: -

The method uses 3 types of configuration form for horizontal wells, namely: -

(a) Well producing from the top (or bottom) of the formation, named as case I

(b) Well only producing from the central section, named as case II

(c) Well with $\mathrm{N}$ intervals open to production (five [5] open intervals, named as case III

For three completion configurations forms of the producing wells, using any of the given configurations, the pseudo skin can be calculated due to partial penetration through which we obtain the productivity index for each case.

The pseudo-skin factor was calculated for both layers MB21 and MC1 of Mishrif Formation, using of Brons and Marting method for the case of partial penetration which results in skin productivity index, the results are presented in Table 12.

\section{RESULTS AND DISCUSSION}

The obtained results from the calculations of PI for horizontal well incorporated within the Mishrif formation in
Table 12. Productivity Index for MB21 and MC1 layers of Mishrif formation due to penetration ratio and pseudo skin for partially completion wells

\begin{tabular}{lccc}
\hline Case & $\mathrm{b}^{\prime}$ & $\mathrm{Sp}$ & $\mathrm{Jh}(\mathrm{STB} / \mathrm{D} / \mathrm{P}$ sia $)$ \\
\hline Layer MB21 $(\mathrm{h}=267.4 \mathrm{ft})$ & & \\
I & 0.2 & 18.8024 & 1.704 \\
& 0.4 & 7.5915 & 3.437 \\
& 0.6 & 3.303 & 5.6293 \\
& 0.8 & 1.1512 & 8.2772 \\
II & 0.2 & 16.0298 & 1.9464 \\
& 0.4 & 6.552 & 3.7958 \\
& 0.6 & 2.8407 & 6.0446 \\
& 0.8 & 0.9778 & 8.6031 \\
III & 0.2 & 9.5921 & 2.9092 \\
& 0.4 & 4.1376 & 5.01 \\
& 0.6 & 1.7677 & 7.294 \\
& 0.8 & 0.5755 & 9.468 \\
Layer MC1 $(\mathrm{h}$ & $=259.2 \mathrm{ft})$ & & \\
I & 0.2 & 18.678 & 1.666 \\
& 0.4 & 7.545 & 3.367 \\
& 0.6 & 3.282 & 5.529 \\
II & 0.8 & 1.1434 & 8.157 \\
& 0.2 & 15.9052 & 1.9055 \\
& 0.4 & 6.5051 & 3.722 \\
& 0.6 & 2.8199 & 5.943 \\
III & 0.8 & 1.1434 & 8.484 \\
& 0.2 & 9.4675 & 2.862 \\
& 0.4 & 4.901 & 4.9286 \\
& 0.6 & 1.747 & 7.1924 \\
\hline
\end{tabular}

Buzurgan oil field were subdivided into two main categories (steady state and unsteady state calculations) with different parameters that affected the PI of horizontal wells, which are mentioned for each layer of the formation. Tables 2-11 show these results. A special calculation code program was done under MATLAB environment to facilitate and ease changes with those parameters of calculations of each case within each layer.

1. Steady state condition. It was shown that the results have been the same trend effect for each parameter on calculations of PI for both MB21 and MC1 layers, except for MC2, because of the lack of data obtained with some real field and properties data.

1.a. all the calculations in Tables 3-7 refer to increase in the PI with the increase of good length, and for all methods especially for the regions in layer MB21 with similar values or nearby of $\mathrm{Kv}$ and $\mathrm{Kh}$, and this is true in coincidence with the effect of this parameter in PI equations.

1.b. Joshi and Giger's models reveal that the PI improves its values toward the increasing of heterogeneity in layer even though Joshi failed with $(\mathrm{Kv} / \mathrm{Kh}=0.1)$, while both of Borisove and Renard and Dupuy models could not sense these changes of Isotropy parameter.

1.c. Also, in this section, all the methods have shown the effect and importance of changing the well length with 
different values of good thickness, this type of results shows how much incremental gain is in productivity with a thick or thin layer of reservoir. A horizontal well results in more produce from thin layers of the reservoir than a thick one, and this is an attribute to wellbore exposure to the reservoir layer.

1.d. With the fixing of good length, variation of drainage area with different values of isotropy, Joshi and Giger methods reveal encouraging results for each drainage with limitations, because of isotropy within formation layer, and this is clear when the drainage area is less than the drainage area of the Base case.

2. Pseudo steady state conditions

2.a. It seems from the results shown in Table 11, that all the methods have an increase the PI with the increasing of well length in both of MB21 and MC1 layers of Mishrif formation [12].

2.b. Also it seems that both of Mutalik et al. Kuchuck methods have similar values, while Babu and odeh is far off in its its PI from the other methods and this is due to the consideration of methodology and consideration of parameters in calculations of the methods.

2.c. Kuchuck and Economides methods are considered close in the results obtained from the calculations, and they are closer and more acceptable within the actual reality, and for the lengths close to them in the field.

3. Completion configuration

3.a. The results obtained in this section of the calculations showed that they are close and for both layers of MB21 and $\mathrm{MC} 1$ and for the various forms or scenarios taken to complete the horizontal wells.

According to the completion configuration and partial penetration well, as seen from the results of calculation using Brons and Martin method, the productivity index of horizontal well gets better and more valuable with increasing the $(\mathrm{hp} / \mathrm{h})$ values, in addition to that, the case III in each layer turned out to be a better choice for completion configuration, because it exposes more formation parts to the well and increasing the exposure production area with the well along the horizontal section that means increasing the productivity index, then increasing the horizontal good production.

4. From the overall calculation results, it seems the method of forecasting and calculations related to PI. It is good evidence of the production chance of commercial quantities of oil and gas in its reservoirs, where the geological and geochemical indications and exploration processes indicated the presence of commercial quantities of hydrocarbon aggregates in the field [13]. These indications used in the oil fields are the relationship between iodine and petroleum systems, the usage of iodine hydro geochemical and pedo-geochemical methods in petroleum exploration and production.

5. As long as the technology of horizontal wells has been widely applied in oil and gas fields and is considered one of the most promising technologies for the development and valorization of oil and gas fields, there are many regions in the world that are considered among the most promising and strategically important at the political, economic and geological levels, which are characterized by a distinct geographical location and have distinct oil fields, that were rich in hydrocarbon aggregates and in excellent reserves, for example the Central Asian region, which has become one of the energy hubs in the world to help the countries to stand out as a significant stable and sustainable source of energy in the region with great resources of supply and low domestic demand [14]. These regions really need such applications (horizontal wells) in the field of production and field development.

\section{CONCLUSIONS}

1. Increasing of productivity index with increasing of the horizontal well lengths with different values of heterogeneity described by isotropy $(\mathrm{Kv} / \mathrm{Kh})$ values.

2. Some methods of PI steady state failed to sense the PI values in some regions of the field.

3. The PI values affected by drainage area, which reveal positive proportionality with the amount of heterogeneity, and for some of the methods used.

4. Regarding the productivity index for the pseudo steady state case, increasing of the well length leads to an increase in the productivity index.

5. Increasing of open intervals to the production leads to an increase in the productivity index of the horizontal well.

\section{NOMENCLATURE}

$\begin{array}{ll}\mathrm{Kh} & \text { Horizontal permeability }-\mathrm{md}(\mathrm{Kh}=\sqrt{ } \mathrm{Ky} / \mathrm{Kx}) \\ \mathrm{Kv} & \text { Vertical permeability - md } \\ \Delta \mathrm{p} & \text { Pressure difference - Psia } \\ \mu \mathrm{o} & \text { Oil viscosity - cp } \\ \mathrm{Bo} & \text { Oil formation volume factor }-\mathrm{bbl} / \mathrm{STB} \\ \mathrm{Reh} & \text { Horizontal well drainage radius - } \mathrm{ft} \\ \mathrm{Rw} & \text { Well radius - } \mathrm{ft} \\ \mathrm{H} & \text { Layer thickness - } \mathrm{ft} \\ \mathrm{L} & \text { Well length - ft } \\ \mathrm{Qh} & \text { Horizontal well flow rate - STB/d } \\ \mathrm{Jh} & \text { Horizontal well productivity index }(\mathrm{PI})-\mathrm{STB} / \mathrm{D} / \\ & \text { Psia } \\ \mathrm{A} & \text { Half major axis of drainage ellipse - } \mathrm{ft} \\ \mathrm{Pwd} & \text { Dimensionless inflow pressure } \\ \mathrm{Sm} & \text { Mechanical skin factor } \\ \mathrm{Si} & \text { Skin factor of an infinite-conductivity, fully pene- } \\ & \text { trating fractures of length L } \\ \mathrm{Scah} & \text { Shape - related skin factor } \\ \mathrm{C} \text { ' } & \text { Shape factor conversion constant = 1.386 } \\ \mathrm{Xe}, \mathrm{Ye} & \text { Dimensions of rectangular drainage area - } \mathrm{ft}\end{array}$




\section{REFERENCES}

[1] I. J. Hussein, Building a Geological Model for the Buzurgan Oil Field/Mishrif Formation, M.Sc. thesis. University of Baghdadcollege of engineering, 2012.

[2] S. D. Joshi, Horizontal Well Technology. Tulsa, OK: Penn well publishing, 1991.

[3] J. P. Borisov, Oil Production using Horizontal and Multiple Deviation Wells. Nedra: Mmcow, 1964. Translated by J. Strauss, and S. D. Joshi (eds.), Phillips Petroleufll Co., the R \& D Library, translation, Bartlesville, Oklahoma, 1984.

[4] F. M. Giger, L. H. Reiss and A. P. Jourdan, "The reservoir engineering aspect of horizontal drilling," in paper SPE 13042 Presented at the SPE 59th Annual Technical Conference and Exhibition, Houston Texas, Sept 16-19, 1984.

[5] G. Renard and J. M. Dupuy, "Influence of formation damage on the flow efficiency of horizontal wells," in paper SPE 19414, presented at the Formation Damage Control Symposium, Lafayette, Louisiana, Feb. 22-2.1, 1990.

[6] D. K. Babu and Aziz S. Odeh, "Productivity of a horizontal well," SPE Reservoir Eng., vol. 4, no. 4, pp. 417-21, 1989.

[7] F. J. Kuchuk, et al., "Pressure-transient analysis for horizontal wells," J. Pet. Technol., vol. 42, no. 8, pp. 974-81, 1990.

[8] M. J. Economides, C. W. Brand and T. P. Frick, "Well configurations in anisotropic reservoirs," SPE Formation Eval., vol. 11, no. 4, pp. 257-62, 1996.

[9] I. J. Hussein, Building a Geological Model for Buzurgan Oil Field/ Mishrif Formation, M.Sc. thesis. University of Baghdad, 2012.

[10] B. Jonathan, "Well completion design," Development in Petroleum Science, vol. 56. Elsevier, 2009.

[11] E. Oaken, and J. Oloro, "A comparative study of the Productivity Index of horizontal well”, Greener Journal of Petroleum and Gas Exploration, vol. 1, no. 1, pp. 7-19, September 2013, ISSN: 2354-2330.

[12] F. A. SAdesina, et al., "Modeling productivity index for long horizontal well," J. Energy Resour. Technol., 2011.

[13] A. Ozdemir, A. Şahinoğlu, M. Jahangir and C. Temizel, "A biophilic material in petroleum exploration and Production: iodine," in Sustainable Materials for Oil and Gas Applications, C. Temizel, M. Sari, H. Canbaz, L. Saputelli and O. Torsater, Eds., Elsevier, 2021, pp. 27-92. https://doi.org/10.1016/B978-0-12-824380-0.00006-2.

[14] C. Temizel, C. H. Canbaz, Y. Palabiyik, R. Moreno, A. K. Najy, J. Xie, H. Wang, R. Ranjith, M. Mofti, and A. Mukanov, "An economical and technical analysis of oil and gas resources of central Asia under demand and Supply Dynamics of world hydrocarbon production," SPE Annual Caspian Technical Conference and Exhibition, 31 Ekim - 02Kasım 2018, Paper Number: SPE-192583-MS, 2018. https://doi.org/10.2118/192583-MS.

\section{Appendix A}

\section{1- Steady state PI models}

\section{Borisove}

$$
\boldsymbol{Q h}=\frac{2 \pi \boldsymbol{h} \Delta p \boldsymbol{k}_{\boldsymbol{h}} /\left(\mu_{\mathrm{o}} \boldsymbol{B}_{\mathrm{o}}\right)}{\ln \left[\left(\frac{4 r_{\text {eh }}}{L}\right)\right]+(\boldsymbol{h l L}) \ln \left[\frac{\boldsymbol{h}}{2 \pi r_{w}}\right]}
$$

Giger

$$
\boldsymbol{Q h}=\frac{2 \pi \boldsymbol{h} \Delta p \boldsymbol{k}_{\boldsymbol{h}} /\left(\mu_{\mathrm{o}} \boldsymbol{B}_{\mathrm{o}}\right)}{\left(\frac{l}{h}\right)\left(\frac{1+\sqrt{1-\left[\frac{L}{2 r_{e h}}\right]^{2}}}{\left[\frac{L}{2 r_{e h}}\right]}\right)+\ln \left[\frac{h}{2 \pi r_{w}}\right]}
$$

\section{Renard and Dupy}

$$
\begin{gathered}
Q \boldsymbol{h}=\frac{2 \pi \boldsymbol{h} \Delta p \boldsymbol{k}_{\boldsymbol{h}}}{\left(\mu_{\mathrm{o}} \boldsymbol{B}_{\boldsymbol{o}}\right)}\left[\frac{1}{\cosh ^{-1}(x)+\left(\frac{h}{L}\right) \ln \left[\frac{h}{2 r_{e h}}\right]}\right] \\
X=2 \boldsymbol{a} / \boldsymbol{L}
\end{gathered}
$$

Joshi

$$
\begin{gathered}
\boldsymbol{Q h}=\frac{2 \pi \boldsymbol{h} \Delta \boldsymbol{p k h} /(\mu \boldsymbol{o} \text { Bo })}{\ln \left[\frac{a+\sqrt{\boldsymbol{a}^{2}-(0.5)^{2}}}{\left(\frac{L}{2}\right)}\right]+\left(\frac{h}{L}\right) \ln \left[\frac{\boldsymbol{h}}{2 \boldsymbol{r}_{w}}\right]} \\
\boldsymbol{a}=\left(\frac{\boldsymbol{L}}{2}\right)\left[0.5+\sqrt{0.25+\left(\frac{2 \boldsymbol{r}_{\text {eh }}}{\boldsymbol{L}}\right)^{4}}\right]
\end{gathered}
$$

\section{2- Pseudo steady state PI models}

Joshi Model [2].

\section{Method I}

$$
\begin{gathered}
J_{h}=\frac{0.00708 K \boldsymbol{K} /\left[\mu_{o} B_{o}\right]}{\ln \left(\frac{r e^{\prime}}{r_{w}}\right)-A^{\prime+S 1+S m+S c a h-C^{\prime}+D q}} \\
r \boldsymbol{e}^{\prime}=\sqrt{A / \pi}
\end{gathered}
$$

Methode II

$$
J_{h}=\frac{0.00708\left(2 X_{e}\right)\left(\mu_{o} B_{o}\right) \sqrt{K_{v} K_{h}}}{\ln \left(\frac{A}{r_{w}}\right)+\ln C h-0.75+S r}
$$

$$
\begin{aligned}
\ln C_{H}= & 6.28\left(\frac{2 y_{e}}{h}\right) \sqrt{\frac{K_{h}}{K_{v}}}\left[\frac{1}{3}-\left(\frac{Y_{w}}{2 Y_{e}}\right)+\left(\frac{Y_{w}}{2 Y_{e}}\right)^{2}\right] \\
& -\ln \left[\sin \left(180 \frac{Z_{w}}{h}\right)-0.5 \ln \left[\left(\frac{2 Y_{e}}{h}\right) \sqrt{\frac{K_{v}}{K_{h}}}\right]\right. \\
& -1.88]
\end{aligned}
$$

Case 1 : $2 \frac{Y_{e}}{K_{v}} \geq 1.5 \frac{X_{e}}{\sqrt{K_{x}}} \gg 0.75 h / \sqrt{K_{v}}$ 
Case $2: 2 \frac{X_{e}}{K_{x}} \geq 2.66 \frac{Y_{e}}{\sqrt{K_{y}}} \gg 1.33 h / \sqrt{K_{v}}$

Case 1

$$
\begin{aligned}
& \mathbf{S}_{\mathbf{R}}=\mathbf{P X Y}+\mathbf{P X Y}^{\prime} \\
& P X Y Z=\left[\frac{2 X e}{L}-1\right]\left[\ln \left(\frac{h}{r_{w}}\right)+0.25 \ln \left(\frac{K_{y}}{K_{v}}\right)\right. \\
& \left.-\ln \left(\sin \frac{180 Z_{w}}{h}\right)-1.84\right] \\
& \boldsymbol{P X} \boldsymbol{Y}^{\prime}=\left(\frac{2\left(\boldsymbol{X}_{\boldsymbol{e}}\right)^{2}}{\boldsymbol{h l}}\right)\left(\sqrt{\frac{\boldsymbol{K}_{\boldsymbol{y}}}{\boldsymbol{K}_{\boldsymbol{v}}}}\right)[\boldsymbol{F}(\boldsymbol{x})+0.5\{(f y 1-f y 2)\}] \\
& X=\frac{L}{4 X e} \quad Y 1=\frac{4 X e+L}{4 X e} \quad Y 2=\frac{4 X e-L}{4 X e} \\
& \boldsymbol{F}(\boldsymbol{x})=-\boldsymbol{x}\left[0.145+\ln (\boldsymbol{x})-0.137\left(\boldsymbol{x}^{2}\right)\right] \\
& \boldsymbol{F}(\boldsymbol{y})=(2-\boldsymbol{Y})\left[0.145+\ln (2-\boldsymbol{Y})-0.137(2-\boldsymbol{Y})^{2}\right] \\
& \mathrm{Y}=\mathrm{Y} 1 \text { or } \mathrm{Y} 2
\end{aligned}
$$

Case 2

$$
\begin{gathered}
S_{R}=P X Y Z+P Y+P X Y \\
S x=\ln \left[\left(\frac{\pi r_{w}}{h}\right)\left(1+\sqrt{\frac{K_{v}}{K_{h}}}\right) \sin \left(\frac{\pi Z_{w}}{h}\right)\right] \\
-\sqrt{\frac{K_{h}}{K_{v}}}\left(\frac{2 h}{L}\right)\left[\frac{1}{3}-\left(\frac{Z_{w}}{h}\right)+\left(\frac{Z_{w}}{h}\right)^{2}\right]
\end{gathered}
$$

Babu and Odeh Model [6].

$$
J \boldsymbol{h}=\frac{0.703 * \mathbf{b} * \sqrt{\mathbf{K x ~ K z}} * \mu \mathbf{g} * \mathbf{z}}{\boldsymbol{T}(\boldsymbol{l n}(\mathbf{C H} * \boldsymbol{A}[* \boldsymbol{r w})-0.75+\mathbf{S R})}
$$

Kuchuk model [7].

$$
\begin{aligned}
& \boldsymbol{J h}=\frac{=0.703 * \mathbf{K H} * \mathbf{h} * \mu \mathbf{g} * \mathbf{z}}{\boldsymbol{T}(\boldsymbol{P} \boldsymbol{w D}+\boldsymbol{S M} *)} \\
& P w D=\frac{h}{2 L} \sqrt{\frac{K_{x}}{K_{z}}}\left(\ln \frac{8 h}{\pi r w} \cot \left(\frac{\pi Z_{w}}{2 h}\right)\right) \\
& +\left(\frac{Z_{w-} \boldsymbol{h}}{\boldsymbol{L}}\right) \sqrt{\frac{\boldsymbol{K}_{x}}{\boldsymbol{K}_{z}}} \\
& S m=\left(\frac{2 \pi L \sqrt{K_{y} K_{z}}}{\mu q}\right) \Delta P s \\
& S m^{*}=\frac{h}{2 L} \sqrt{\frac{K_{x}}{K_{z}}} * S m
\end{aligned}
$$

Economides Model [8].

$$
\begin{gathered}
J=\frac{0.73 * \operatorname{Kavg} * X e * \mu * z}{T\left(P D+\frac{X e}{2 \pi L}\right) \sum S} \\
P D=\frac{X e C H}{4 \pi h}+\frac{X e}{2 \pi L} S x \\
S x=\ln \left(\frac{h}{2 \pi r w}\right)-\frac{h}{6 L}+S e \\
S e=\frac{h}{L}\left(\left(\frac{2 * Z w}{h}\right)-0.5\left(\frac{2 * Z w}{h}\right)^{2}\right. \\
-\ln \left(\sin \left(\frac{\pi * Z w}{h}\right)\right)
\end{gathered}
$$

